\title{
Methodological approach to the elaboration of the analytical procedure of the antioxidant activity determination of the Schisandra chinensis (Turcz) Baill. extracts
}

\author{
Nataliia Hudz ${ }^{1 *}$, Vladimira Horčinová Sedláčková2, \\ Oksana Yezerska', Mykhailo Zhurba ${ }^{3}$, Ján Brindza² \\ ${ }^{1}$ Danylo Halytsky Lviv National Medical University, Department of Drug Technology \\ and Biopharmaceutics, Lviv, Ukraine \\ ${ }^{2}$ Slovak University of Agriculture in Nitra, Institute of Plant and Environmental Sciences, Nitra, Slovakia \\ ${ }^{3}$ M.M. Gryshko National Botanical Garden of the National Academy of Sciences of Ukraine, \\ Department of Fruit Plants Acclimatization, Kyiv, Ukraine \\ ORCID \\ Nataliia Hudz https://orcid.org/0000-0002-2240-0852 \\ Vladimíra Horčinová Sedláčková https://orcid.org/0000-0002-5844-8938 \\ Oksana Yezerska https://orcid.org/0000-0001-8543-2723 \\ Mykhailo Zhurba https://orcid.org/0000-0001-5318-3961 \\ Jan Brindza https://orcid.org/0000-0001-8388-8233
}

Article Details:

Received: 2021-07-10

Accepted: 2021-08-05

Available online: 2021-11-30

DOI: https://doi.org/10.15414/ainhlq.2021.0024

\begin{abstract}
The DPPH assay provides an easy and rapid way to evaluate the antioxidant activity of herbal preparations. The most important stage of the elaboration of the analytical procedure of total antioxidant activity measured by the DPPH test is to select the volume of an extract or its appropriate dilution for the determination of the reliable total antioxidant activity of the extract. If the concentration of antioxidants is too high in an extract, the kinetic curves of antioxidant activity changes on time are more parallel to axis $X$ (time) and what is more, the total antioxidant activity does not depend on the volume of the extract. The analytical procedure of the antioxidant activity determination of the Schisandra chinensis (Turcz) Bail. extracts was elaborated, namely a volume and dilution of the extract was selected, rutin was chosen for the calibration curve. The calibration curve was plotted in the concentration range of 95-305 mg/L $\left(y=0.228 x+7.0992, R^{2}=0.9945\right)$. The results suggest that the leaves of $S$. chinensis are a valuable source of antioxidant compounds with significant antioxidant activity. The antioxidant activity was evaluated by the DPPH test. It was equal to $227.2-443.6 \mathrm{mg} / \mathrm{L}$ in the extracts or $1.14-2.22 \mathrm{mg} / \mathrm{g}$ in the leaves of rutin-equivalents depending on the particle size. Additionally, it was established that particle size in the range of 2 to $3 \mathrm{~mm}$ was optimal for the preparation of Schisandra chinensis extracts as the antioxidant activity was the highest. The ethanol absorption coefficient is a main technological parameter in the pharmaceutical manufacture of extracts. The absorption coefficient of the Schisandra chinensis leaves for $70 \%$ ethanol was in the range of 3.4 to $6.5 \mathrm{ml} / \mathrm{g}$ and depended on the particle size.
\end{abstract}

Keywords: Schisandra chinensis, ethanolic extracts, antioxidant activity, DPPH test

\footnotetext{
*Corresponding Author: Nataliia Hudz, Danylo Halytsky Lviv National Medical University, Department of Drug Technology and Biopharmaceutics, Str. Pekarska 69, 79010 Lviv, Ukraine $\triangle$ nataligudz@ukr.net
} 


\section{Introduction}

Schisandra chinensis (Turcz) Bail., Chinese magnolia vine belongs to the family of Magnoliaceae. Schisandra chinensis is widely distributed in China, Japan, Korea, and other countries due to its cultivation (Panossian and Wikman 2008; Lai et al., 2015; Qui et al., 2018; Hu et al., 2020). This plant is described in many Pharmacopeias. Among them are the Chinese Pharmacopeia, the Japanese one, the Pharmacopeia of the United State of America, and the State Pharmacopeia of Ukraine (Szopa et al., 2018; Qui et al., 2018; Hu et al., 2020).

The principal active substances of Schisandra chinensis are lignans and triterpenes (Song et al., 2016; Szopa et al., 2018; Qui et al., 2018; Hu et al., 2020). Fruits are rich in organic acids, especially citric acid (Hu et al., 2020). According to $\mathrm{Hu}$ et al., there existed a strong correlation between the total phenolic content of extracts of fruits and antioxidant activity determined by the DPPH test (Hu et al., 2020).

Modern medical researches prove that $S$. chinensis contains multiple active components which can protect liver cells (Ip and Ko, 1996; Ip et al., 2007; Teraoka et al., 2012), restrain oxidation (Jung et al., 2000; Sheng et al., 2011), prevent senility (Nishiyama et al., 1996; Hsieh et al., 1999; Hsieh et al., 2001; Kang et al., 2005), improve human body immunity ability (Mizoguchi et al., 1991). It can have a positive influence on the pulmonary system, kidney, liver, skin, central nervous system, etc. (Kim et al., 2004; Fu et al., 2008; Lai et al., 2015; Gao et al., 2016; Huang et al., 2017; Li et al., 2019; Liu et al., 2019). The renoprotective effects of the Schisandra chinensis extract are related to its antiapoptotic and antioxidant abilities, which induced the attenuation of CsA-induced autophagic cell death (Lai et al., 2015). Schizandrin B reduces UVB-irradiation damages of skin fibroblasts and epidermal keratinocytes (Gao et al., 2016).

There are some studies on the anti-inflammatory activity of Schisandra chinensis extracts and some individual lignans (Song et al., 2016; Szopa et al., 2018; Qui et al., 2018). The leaves of Schisandra chinensis are richer in polyphenolic compounds (Mocan et al., 2014). However, there are few studies related to Schisandra chinensis leaves extracts. Some authors indicate that Schisandra chinensis leaves are a valuable source of flavonoids with important antioxidants (Yu et al., 2017) and antimicrobial activities (Mocan et al., 2014). The Schisandra chinensis leaves extract showed stronger antimicrobial activity compared to the fruit extract (Mocan et al., 2014).
To widen the potential use of $S$. chinensis in antioxidant biomedicine, the present study was carried out to study antioxidant activities of extracts from the leaves of S. chinensis of different particle sizes, using 1,1-diphenyl2-picrylhydrazyl (DPPH) radical scavenging activity. Therefore, the purpose of our studies was to evaluate the antioxidant activity of the extracts prepared from the powdered leaves of Schisandra chinensis of the different sizes: $1-2 \mathrm{~mm}, 2-3 \mathrm{~mm}, 3-4 \mathrm{~mm}$, and 5-7 $\mathrm{mm}$. For the correct evaluation of antioxidant activity by the DPPH method, it is necessary to select an appropriate ratio of a solution of DPPH to an extract. For that reason, one more aim was to elaborate an appropriate analytical procedure for the evaluation of the antioxidant activity of the extracts by the DPPH method.

\section{Material and methodology}

While carrying out this research, the following methods were used: analysis, synthesis, systematization, and comparison for processing published scientific data; technological method (remaceration); spectrophotometric method for the elaboration of the analytical procedure of the determination of the total antioxidant activity by DPPH test.

\section{Plant material}

Schisandra chinensis leaves were collected in the Arboretum Mlynany (Slovakia) in the middle of July of 2021. The specimen was stored in the herbarium of Institute of Plant and Environmental Sciences, Slovak University of Agriculture in Nitra. The voucher specimen number is Sch-2.

\section{Reagents}

The following reagents were used: ethanol $96 \%$ (manufacturer "Centrachem" (Slovakia)), DPPH ("Sigma Aldrich"), and rutin hydrate ("Sigma Aldrich").

\section{Extraction}

The dry leaves were ground into powder and fractionated through different sieves $(1,2,3,5$, and $7 \mathrm{~mm}$ ) before the preparation of extracts.

Four extracts were prepared, using the different fractions of the powdered leaves. The remaceration consisted of maceration for 24 hours and the following two macerations for a period of $3 \mathrm{~h}$ for each one. The filtration was performed after each maceration and the obtained extracts were combined. Therefore, the total maceration accounted for 30 hours (24 hours + 
Table 1 Characterization of the obtained extracts

\begin{tabular}{|c|c|c|c|c|c|}
\hline \multirow{2}{*}{$\begin{array}{l}\text { Number of } \\
\text { the extracts }\end{array}$} & \multirow{2}{*}{$\begin{array}{l}\text { Particle size } \\
\text { (mm) }\end{array}$} & \multirow{2}{*}{$\begin{array}{c}\text { Mass of the } \\
\text { leaves (g) }\end{array}$} & \multicolumn{2}{|c|}{ Added volume of ethanol/obtained volume of an extract } & \multirow{2}{*}{$\begin{array}{l}\text { Total volume of } \\
\text { the extract }(\mu \mathrm{L})\end{array}$} \\
\hline & & & main maceration & additional two macerations & \\
\hline Extract 1 & $1-2$ & 1.54 & $10 / 0$ & $\begin{array}{l}5.0 / 4.2 \\
5.0 / 3.3\end{array}$ & 7.5 \\
\hline Extract 2 & $3-4$ & 2.50 & $15 / 3.3$ & $\begin{array}{l}5.0 / 4.5 \\
5.0 / 5.0\end{array}$ & 12.5 \\
\hline Extract 3 & $2-3$ & 2.50 & $15 / 2.4$ & $\begin{array}{l}5.1 / 3.6 \\
7.0 / 7.0\end{array}$ & 12.5 \\
\hline Extract 4 & $5-7$ & 2.50 & $15 / 6.6$ & $\begin{array}{l}3.2 / 2.4 \\
5.0 / 2.8\end{array}$ & 12.5 \\
\hline
\end{tabular}

2 macerations $\times 3$ hours $=30$ hours). Features of the preparation of the extracts are provided in Table 1.

\section{DPPH free radical scavenging activity assay}

The two described analytical procedures were put in base of the evaluation of the extracts of Schisandra chinensis (Hudz et al., 2017; Hu et al., 2020), where authors used ascorbic acid as a positive control. In our study we used rutin. Additionally, Mocan et al. (2014) used quercetin as a positive control.

DPPH was dissolved in $96 \%$ ethanol to a final approximate concentration of $0.003 \%$. In the free radical scavenging activity assay, $1950 \mu \mathrm{L}$ of the DPPH solution was added to $2000 \mu \mathrm{L}$ tubes, followed by $50 \mu \mathrm{L}$ of the extract or its dilution. The solutions were mixed and incubated in the dark at room temperature. The absorbance was recorded at a wavelength of $515 \mathrm{~nm}$ (As). The mixture of $1950 \mu \mathrm{L}$ of $96 \%$ ethanol solution with $50 \mu \mathrm{L}$ of the extract was used as a blank for the extract. The value A0 was recorded when $1950 \mu \mathrm{L}$ of DPPH solution was mixed with $50 \mu \mathrm{L}$ of ethanol after incubation under the former conditions. $96 \%$ ethanol solution was used as a blank for the DPPH solution.

To compare the free radical scavenging activity of the four extracts, the rutin equivalents of each sample were calculated. Rutin was dissolved in $50 \%$ ethanol solution and diluted to different five concentrations. Then $50 \mu \mathrm{L}$ of each solution was mixed with DPPH solution. The reaction mixtures were incubated for $40 \mathrm{~min}$. Their absorbance was recorded at a wavelength of $515 \mathrm{~nm}$ each $10 \mathrm{~min}$. The mixture of $1950 \mu \mathrm{L}$ of $96 \%$ ethanol solution with $50 \mu \mathrm{L}$ of each rutin solution was used as a blank for each rutin solution.

In addition, we studied the stability of reaction mixtures or, in other words, we studied the kinetics of the reaction of DPPH with the extracts and rutin depending on the time.

\section{Statistical analysis}

All the analyses of the DPPH test for each extract, its dilution, and solutions of rutin were carried out in triplicate and the results were expressed as a mean value \pm standard deviation (SD).

\section{Results and discussion}

Herbal preparations are used as an alternative source of medicines to mitigate the diseases associated with oxidative stress (Priya and Nethaji, 2015). The free-radical scavenging activity of the extracts was evaluated using the widely used 2,2-diphenyl-1picrylhydrazyl (DPPH) test (Sheng et al., 2011; Mocan et al., 2014; Ivanišová et al., 2017; Vergun et al., 2018, 2021; Grygorieva et al, 2020; Shelepova et al., 2020; Tvrdá et al., 2020; Mňahončaková et al., Vinogradova et al., 2021). The DPPH assay provides an easy and fast mode to estimate antioxidant activity. This test is based on electron-transfer. DPPH produces a violet solution in ethanol or methanol. The reduction of DPPH in the presence of an antioxidant or mixture of antioxidants leads to the formation of non-radical form DPPH-H of yellow or yellowish colour (Sheng et al., 2011; Mocan et al., 2014; Rachman et al., 2015). According to our studies, the colour of final mixtures can be light purple or yellow depending on the concentration of antioxidants.

Various modifications and optimizations of DPPH assay are described for their adaptation to tested extracts or are the invention of researchers (Sheng et al., 2011; Mocan et al., 2014; Hu et al., 2020).

The most important stage of the development of the analytical procedure of the total antioxidant activity measured by the DPPH test is to select the volume of an extract or its appropriate dilution for the determination of the reliable total antioxidant activity of the extract. From our experience, if the concentration of antioxidants is too high in an extract, 


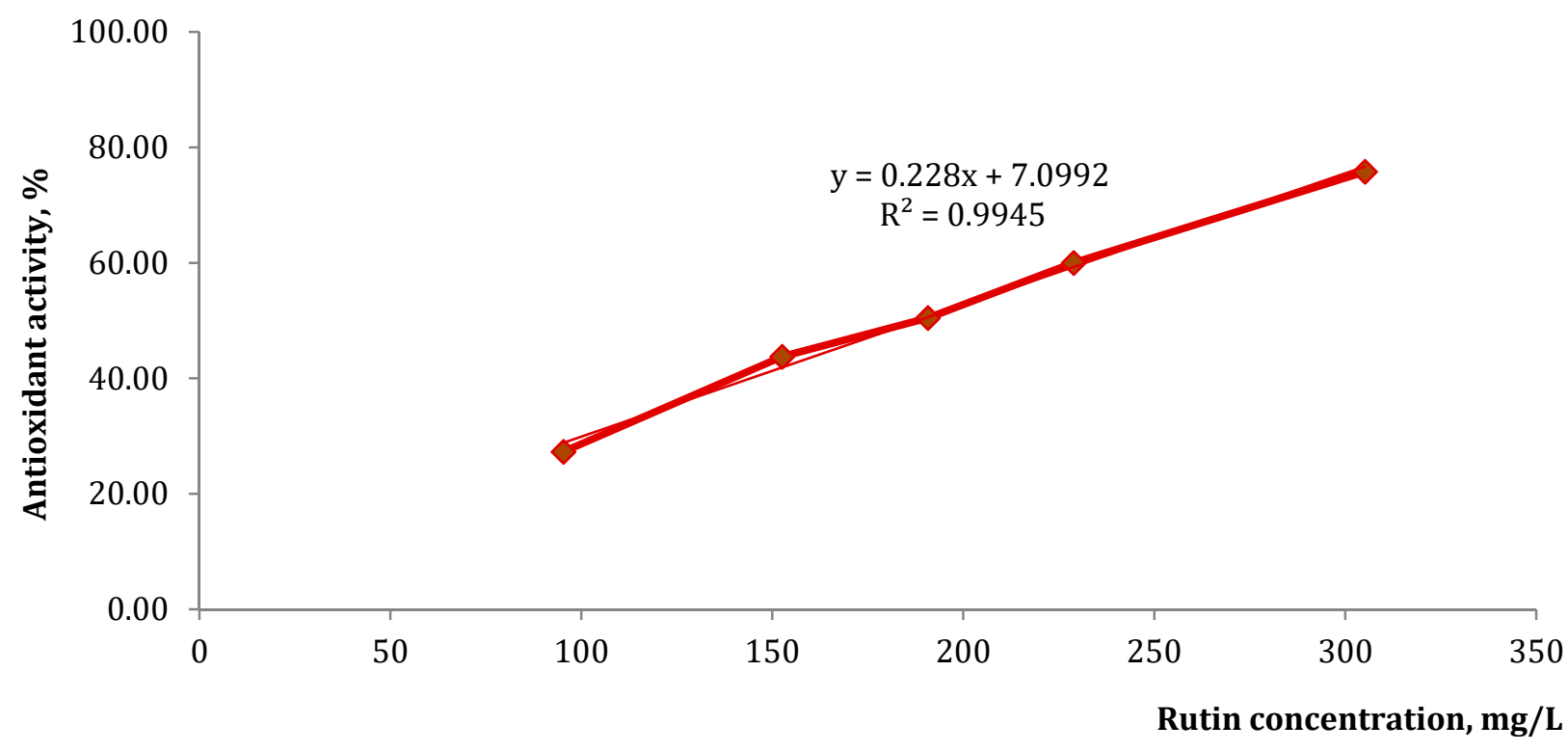

Figure 1 Calibration curve of rutin

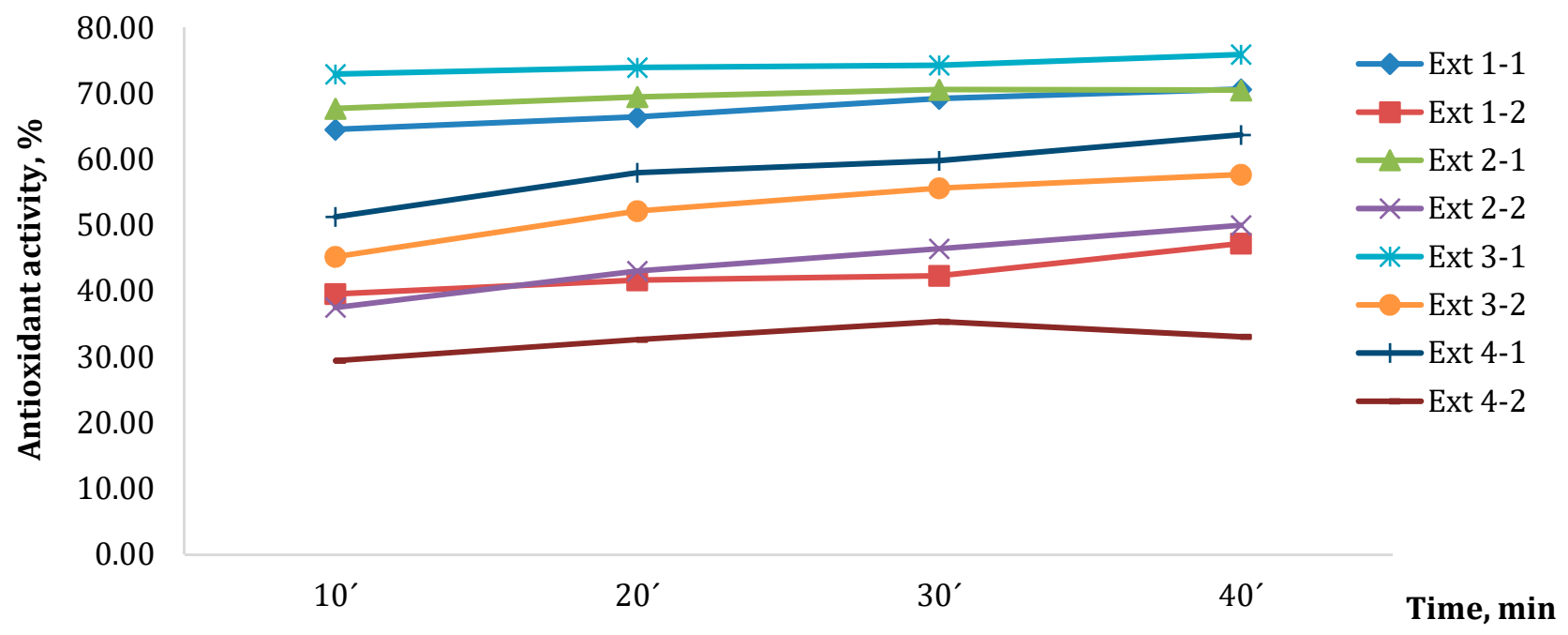

Figure 2 Dependence of the antioxidant activity of the extracts of Schisandra chinensis (Turcz) Bail. on time Ext 1-1, Ext 2-1, Ext 3-1, Ext 4-1 - extracts 1, 2, 3 and 4 without dilution and Ext 1-2, Ext 2-2, Ext 3-2, Ext 4-2 - extracts 1, 2,3 and 4 diluted twice by $70 \%$ ethanol

namely if the content of biologically active substances is very large and an appropriate dilution was not selected, then DPPH is reduced very quickly without dependence on dilution and final mixtures get yellow. In that case, the kinetic curves of antioxidant activity changes on time are more parallel to axis $X$ (time), and, what is more, the total antioxidant activity is equal to $80-85 \%$ and did not depend on the volume of the extract of beebread (20-50 $\mu$ l) (Hudz et al., 2017). In other words, the higher the rate of DPPH consumption is, the more powerful the antioxidant potential (Mocan et al., 2014). Therefore, it is necessary to decrease the volume of the sample or dilute it.
According to the literature, DPPH has an absorption maximum at a wavelength of 514-517 nm (Ivanišová et al., 2017; Shelepova et al., 2019; Vergun et al., 2019, 2021; Grygorieva et al, 2020; Hu et al., 2020; Tvrdá et al., 2020). Reducing a colour intensity of a reaction mixture is carried out by various authors at the time range of 4-15 minutes to 1 hour (Sheng et al., 2011; Mocan et al., 2014; Hu et al., 2020).

The results obtained by the DPPH test were presented as rutin equivalents, $\mathrm{mg} / \mathrm{L}$ and $\mathrm{mg} / \mathrm{g}$ (Table 2 ). The percentage of DPPH consumption was converted to rutin equivalents by using a calibration curve $\left(y=0.228 x+7.0992, R^{2}=0.9945\right)$ with the rutin 
Table 2 Antioxidant activity of the Schisandra chinensis (Turcz) Bail. extracts expressed in \%, mg/L and mg/g of rutinequivalents

\begin{tabular}{ccccc}
\hline № & \multicolumn{2}{c}{ Antioxidant activity (\%), mean \pm SD } & $\begin{array}{c}\text { Concentration of rutin- } \\
\text { equivalents (mg/L) in the } \\
\text { extract* }\end{array}$ & $\begin{array}{c}\text { Concentration of rutin- } \\
\text { equivalents (mg/g), in the } \\
\text { leaves* }\end{array}$ \\
\hline $\mathbf{1}$ & $70.6 \pm 0.1$ & $47.2 \pm 0.8$ & $351.8 \pm 6.0$ & 1.76 \\
$\mathbf{2}$ & $70.5 \pm 1.3$ & $50.0 \pm 1.3$ & $376.3 \pm 9.8$ & 1.88 \\
$\mathbf{3}$ & $75.9 \pm 0.9$ & $57.7 \pm 0.9$ & $443.6 \pm 6.9$ & 2.22 \\
$\mathbf{4}$ & $63.7 \pm 1.5$ & $33.0 \pm 0.6$ & $227.2 \pm 4.1$ & 1.14 \\
\hline
\end{tabular}

Notes: * calculations were performed on the values of AA of the diluted extracts

Table 3 Calculations of the experimental determination of the absorption coefficient of $70 \%$ ethanol

\begin{tabular}{lcl}
\hline № & Particle size (mm) & Calculations \\
\hline $\mathbf{1}$ & $1-2$ & $\mathrm{X} 1=(10-0): 1.54=6.5 \mathrm{ml} / \mathrm{g}$ \\
$\mathbf{2}$ & $3-4$ & $\mathrm{X} 2=(15-3.3): 2.5=4.7 \mathrm{ml} / \mathrm{g}$ \\
$\mathbf{3}$ & $2-3$ & $\mathrm{X} 3=(15-2.4): 2.5=5.0 \mathrm{ml} / \mathrm{g}$ \\
$\mathbf{4}$ & $5-7$ & $\mathrm{X} 4=(15-6.6): 2.5=3.4 \mathrm{ml} / \mathrm{g}$ \\
\hline
\end{tabular}

solutions in the concentration range of $95-305 \mathrm{mg} / \mathrm{L}$ (Figure 1).

From Figure 1 we can observe that the higher the rate of DPPH consumption is, the more powerful is the antioxidant potential. For undiluted Schisandra chinensis extracts the antioxidant activity was in the range of 70-76\% independing on particle size in the case of extracts 1,2 , and 3 . This pointed to an inappropriate ratio of antioxidants content and DPPH. Therefore, firstly we diluted our extracts twice and measured the antioxidant activity.

In Figure 2 we presented the dependence of the antioxidant activity of the undiluted and diluted extract on the time. The ratio of an extract to a final dilution was 1 to 2 .

Our studies are in line with studies performed by Sheng et al. (2011) and Rachman et al. (2015). Increasing the concentration of compounds with antioxidant activities enhances the antioxidant activity of a reaction mixture (Sheng et al., 2011; Rachman et al., 2015). Moreover, such an increase in the concentration of compounds with antioxidant activities leads to that the kinetic curves of antioxidant activity changes on concentration are parallel to axis $X$ (Sheng et al., 2011; Rachman et al., 2015).

From Table 2 we can observe that the total antioxidant activity of the native extracts is equal to $63.7-75.9 \%$. This antioxidant activity did not correlate with the values of the antioxidant activity of the same diluted extracts except for extract 4 . We can suppose that it is necessary to select the appropriate dilution of an extract of the total antioxidant activity of this undiluted extract exceeds $64 \%$. Moreover, the kinetic curves of the dependence of antioxidant activity on time are more parallel to axis $X$ for extracts 1-3 that is in line with the studies performed for the extracts of beebread (Hudz et al., 2017).

Furthermore, it was established that particle size in the range of $2-3 \mathrm{~mm}$ is optimal for the preparation of Schisandra chinensis extracts. We observed in our study that an increase in the surface area available for molecular transport contributes to a more extensive mass transfer of compounds with antioxidant activity into an extract if not considering extract 1.

Additionally, rutin was selected as a marker for the DPPH test as such flavonoid glycosides as rutin, hyperoside, quercitrin, and isoquercitrin and flavonoid aglycones as myricetin, kaempferol, and quercetin were identified in the extract of the Schisandra chinensis fruits Bail (Mocan et al., 2014; Tvrdá et al., 2020). Moreover, rutin was dominated flavonoid among glycosides in the extract (Tvrdá et al., 2020).

The DPPH assay showed that the free-radical scavenging activity of the extract from fruits was $5.93 \mathrm{mg}$ of Trolox equivalents/g d.w. (Tvrdá et al., 2020). The antioxidant activity of $S$. chinensis leaves was $26.87 \pm 0.84 \mathrm{mg} \mathrm{QE} / \mathrm{g}$ of plant material, while the antioxidant activity of $S$. chinensis fruits was $7.80 \pm 0.55 \mathrm{mg}$ QE/g of plant material (Mocan et al., 2014).

We cannot compare our results with published data as antioxidant activity was expressed in rutin equivalents in our studies. 
The ethanol absorption coefficient is a main technological parameter in the pharmaceutical manufacture of extracts (Yezerska et al., 2021). The results of the technological studies are provided in Table 3. It was revealed that the coefficient of alcohol absorption of the crushed leaves depended on the size of particles.

We observed such regularity: the more particle size, the less was the absorption coefficient (Table 3).

\section{Conclusion}

The analytical procedure of the antioxidant activity determination of the Schisandra chinensis extracts by the DPPH test was developed from a point of view of choosing a volume and dilution of the extracts, marker for the calculation of the antioxidant activity of the extracts. The calibration curve was plotted in the concentration range of 95 to $305 \mathrm{mg} / \mathrm{L}$ of rutin $\left(y=0.228 x+7.0992, R^{2}=0.9945\right)$. The results suggest that the leaves of Schisandra chinensis are a valuable source of antioxidant compounds with significant antioxidant activity. The antioxidant activity of the Schisandra chinensis extracts (1: 5) was equal to $227.2-443.6 \mathrm{mg} / \mathrm{L}$ rutin-equivalents depending on the particle size. Additionally, it was established that particle size in the range of $2-3 \mathrm{~mm}$ was optimal for the preparation of Schisandra chinensis extracts as the antioxidant activity was the highest. This study established the basis for future research into the elaboration of the Schisandra chinensis extracts from leaves.

\section{Conflicts of interest}

The authors declare no conflict of interest.

\section{Ethical statement}

This article does not contain any studies that would require an ethical statement.

\section{Funding}

This work was supported by SAIA for the scholarship for the research related to the development of herbal products on the base of adaptogens and performed at the Slovak University of Agriculture in Nitra (Slovakia), 2021.

\section{Acknowledgments}

The publication was prepared with the active participation of researchers in international network AgrobioNet.

\section{References}

Fu, M., Sun, Z.H., Zong, M., He, X.P., Zuo, H.C., \& Xie, Z.P. (2008). Deoxyschisandrin modulates synchronized $\mathrm{Ca}^{2+}$ oscillations and spontaneous synaptic transmission of cultured hippocampal neurons. Acta Pharmaceutica Sinica, 29(8), 891-898.

http://dx.doi.org/10.1111/j.1745-7254.2008.00821.x

Gao, C., Chen, H., Niu, C., Hu, J., \& Cao, B. (2016). Protective effect of Schizandrin B against damage of UVB irradiated skin cells depend on inhibition of inflammatory pathways. Bioeng, 8, 36-44.

Grygorieva, O., Klymenko, S., Vergun, O., Shelepova, O., Vinogradova, Y., Ilinska, A., Horčinová Sedláčková, V., \& Brindza, J. (2020). Chemical composition of leaves of Chinese Quince (Pseudocydonia sinensis (Thouin) C.K. Schneid.). Agrobiodiversity for Improving Nutrition, Health and Life Quality, 4, 78-93. $\underline{\text { https://doi.org/10.15414/ }}$ agrobiodiversity.2020.2585-8246.078-93

Hsieh, M.T., Tsai, M.L., Peng, W.H., \& Wu, C.R. (1999). Effects of Fructus schizandrae on cycloheximideinduced amnesia in rats. Phytotherapy Research, 13(3),

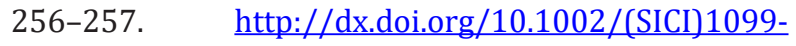
1573(199905)13:3<256::AID-PTR435>3.0.CO;2-H

Hsieh, M.T., Wu, C.R., Wang, W.H., \& Lin, L.W. (2001). The ameliorating effect of the water layer of fructus Schisandrae on cycloheximide-induced amnesia in rats: interaction with drugs acting at neurotransmitter receptors. Phytotherapy Research, 43(1), 17-22. http://dx.doi.org/10.1006/phrs.2000.0756

Hu, G., Qi, Z., Wang, A., \& Jia, J. (2020). Effects of deacidification on composition of Schisandra chinensis ethanolic extract and studies on acute toxicity in mice. Molecules, 25(24), 6038. https://doi.org/10.3390/molecules25246038

Huang, H., Shen, Z., Geng, Q., Wu, Z., Shi, P., Miao, X. (2017). Protective effect of Schisandra chinensis bee pollen extract on liver and kidney injury induced by cisplatin in rats. Biomed Pharmacotherapy, 95, 1765-1776. http://dx.doi.org/10.1016/j.biopha.2017.09.083

Hudz, N., Ivanova, R., Brindza, J., Grygorieva, O., Schubertová, Z., \& Ivanišová, E. (2017). Approaches to the determination of antioxidant activity of extracts from bee bread and safflower leaves and flowers. Potravinarstvo Slovak Journal of Food Sciences, 11(1), 480-488. https://doi.org/10.5219/786

Ip, S.P., \& Ko, K.M. (1996). The crucial antioxidant action of schisandrin B in protecting against carbon tetrachloride hepatotoxicity in mice: a comparative study with butylated hydroxytoluene. Biochemical Pharmacology, 52(11), 1687-1693. http://dx.doi.org/10.1016/S0006-2952(96)00517-57

Ip, S.P., Poon, M.K., Wu, S.S., Che, C.T., Ng, K.H., Kong, Y.C., Ko, K.M. (2007). Effect of schisandrin B on hepatic glutathione antioxidant system in mice: protection against carbon tetrachloride toxicity. Planta Medica, 61(05), 398-401. http://dx.doi.org/10.1055/s-2006-958123 
Ivanišová, E., Mittuchová, K., Mareček, J., \& Frančáková, H. (2017). Small berries-attractive source of bioactive compounds for consumers. Agrobiodiversity for Improving Nutrition, Health and Life Quality, 1, 188-194. $\quad$ http://dx.doi.org/10.15414/ agrobiodiversity.2017.2585-8246.188-1

Jung, G.T., Ju, I.O., Choi, J.S., \& Hong, J.S. 2000. The antioxidative, antimicrobial and nitrite scavenging effects of Schisandra chinensis RUPRECHT (Omija) seed. Korean Journal of Food Science and Technology, 32, 928-935.

Kang, S.Y., Lee, K.Y., Koo, K.A., Yoon, J.S., Lim, S.W., Kim, Y.C., Sung, S.H. (2005). ESP-102, a standardized combined extract of Angelica gigas, Saururus chinensis and Schizandra chinensis, significantly improved scopolamine-induced memory impairment in mice. Life Sciences, 76(15), 1691-1705. http://dx.doi.org/10.1016/j.lfs.2004.07.029

Kim, S.R., Lee, M.K., Koo, K.A., Kim, S.H., Sung, S.H., Lee, N.G., Markelonis, G.J., Oh, T.H., Yang, J.H., Kim, Y.C. (2004). Dibenzocyclooctadiene lignans from Schisandra chinensis protect primary cultures of rat cortical cells from glutamate-induced toxicity. Journal of Neuroscience Research, 76(3), 397-405.

http://dx.doi.org/10.1002/jnr.20089

Lai, Q., Wei, J., Mahmoodurrahman, M., Zhang, C., Quan, S., Li, T., Yu, Y. (2015). Pharmacokinetic and nephroprotective benefits of using Schisandra chinensis extracts in a cyclosporine A-based immunesuppressive regime. Drug Design, Development and Therapy, 9, 4997-5018. http://dx.doi.org/10.2147/DDDT.S89876

Li, X., Liu, Y., Yue, W., Tan, Y., Wang, H., Zhang, L., Chen, J. (2019). A compound of chinese herbs protects against alcoholic liver fibrosis in rats via the TGF- $\beta 1 /$ Smad signaling pathway. Evil Complementary And Alternative Medicine, 2019, 9121347.

http://dx.doi.org/10.1155/2019/9121347

Liu, X., Chen, H., Su, G., Song, P., Jiang, M., \& Gong, J. (2019). Animal research and a chemical composition analysis of a Chinese prescription for pulmonary fibrosis: Yangfei Huoxue Decoction. Journal of Ethnopharmacology, 245. http://dx.doi.org/10.1016/j.jep.2019.112126

Mizoguchi, Y., Shin, T., Kobayashi, K., \& Morisawa, S. 1991. Effect of gomisin A in an immunologically-induced acute hepatic failure model. Planta Medica, 57(1), 11-14. http://dx.doi.org/10.1055/s-2006-960006

Mňahončaková, E., Vergun, O., Grygorieva, O., Horčinová Sedláčková, V., Ivanišová, E., Fatrcová Šramková, K., Hrušová, M., Brindza, J. (2021). Evaluation of the antioxidant potential of Capsicum annuum L., C. baccatum L., and C. chinense Jacq. cultivars. Acta Scientiarum Polonorum Technologia Alimentaria, 20(2), 223-336. https://dx.doi.org/10.17306/J.AFS.2021.0941

Mocan, A., Crișan, G., Vlase, L., Crișan, O., Vodnar, D.C., Raita, O., Gheldiu, A.M., Toiu, A., Oprean, R., Tilea, I. (2014). Comparative studies on polyphenolic composition, antioxidant and antimicrobial activities of Schisandra chinensis leaves and fruits. Molecules, 19(9), 1516215179. https://doi.org/10.3390/molecules190915162
Nishiyama, N., Chu, P.J., \& Saito, H. (1996). An herbal prescription, S-113m, consisting of biota, ginseng and schizandra, improves learning performance in senescence accelerated mouse. Biological and Pharmaceutical Bulletin, 19(3), 388-393. http://dx.doi.org/10.1248/bpb.19.388

Panossian, A., \& Wikman, G. (2008). Pharmacology of Schisandra chinensis Bail.: An overview of Russian research and uses in medicine. Journal of Ethnopharmacology, 118, 183-212.

Priya, S., \& Nethaji, S. (2015). Evaluation of antioxidant activity of leaf and bark extracts of Diospyros virginiana in rats. International Journal of ChemTech Research, 8(3), 1032-1035.

Qiu, F., Liu, H., Duan, H., Chen, P., Lu, S.J., Yang, G.Z, \& Lei, X.X. (2018). Isolation, structural elucidation of three new triterpenoids from the stems and leaves of Schisandra chinensis (Turcz) Baill. Molecules, 23(7), 1624. https://doi.org/10.3390/molecules23071624

Rahman, M.M., Islam, M.B., Biswas, M., Khurshid Alam, A.H. (2015). In vitro antioxidant and free radical scavenging activity of different parts of Tabebuia pallida growing in Bangladesh. BMC Research Notes, 8, 621. https://doi.org/10.1186/s13104-015-1618-6

Shelepova, O., Vinogradova, Yu., Vergun, O., Grygorieva, O., Brindza, J. (2020). Assessment of flavonoids and polyphenol compound accumulation in invasive Solidago canadensis L. in Slovakia. Potravinarstvo Slovak Journal of Food Sciences, 14(1), 587-594. https://doi.org/10.5219/1378

Shelepova, O., Vinogradova, Yu., Vergun, O., Grygorieva, O., Brindza, J. (2019). Invasive Solidago canadensis L. as a resource of valuable biological compounds. Potravinarstvo Slovak Journal of Food Sciences, 13(1), 280-286. http://doi.org/10.5219/1125

Sheng, Y., Liu, Y., Huang, X.D., Yuan, G.X., \& Guan, M. (2011). Purification, chemical characterization and in vitro antioxidant activities of alkali-extracted polysaccharide fractions isolated from the fruits of Schisandra chinensis. Journal of Medicinal Plants Research, 5(24), 5881-5888.

Song, Q.-Y., Gao, K., \& Nan, Z.-B. (2016). Highly oxygenated triterpenoids from the roots of Schisandra chinensis and their anti-inflammatory activities. Journal of Asian Natural Products Research, 18, 189-194. https://doi.org/10.1080/10286020.2015.1056165

Szopa, A., Dziurka, M., Warzecha, A., Kubica, P., KlimekSzczykutowicz, M., \& Ekiert, H. (2018). Targeted lignan profiling and anti-inflammatory properties of Schisandra rubriflora and Schisandra chinensis extracts. Molecules, 23, 3103. https://doi.org/10.3390/molecules23123103

Szopa, A., Ekiert, R., \& Ekiert, H. (2017). Current knowledge of Schisandra chinensis (Turcz.) Baill. (Chinese magnolia vine) as a medicinal plant species: a review on the bioactive components, pharmacological properties, analytical and biotechnological studies. Phytochemistry 
reviews : proceedings of the Phytochemical Society of Europe, 16(2), 195-218. https://doi.org/10.1007/s11101-016-9470-4

Teraoka, R., Shimada, T., \& Aburada, M. (2012). The molecular mechanisms of the hepatoprotective effect of gomisin A against oxidative stress and inflammatory response in rats with carbon tetrachloride-induced acute liver injury. Biological and Pharmaceutical Bulletin, 35(2), 171-177. http://dx.doi.org/10.1248/bpb.35.171

Tvrdá, E., Michalko, J., Árvay, J., Vukovic, N.L., Ivanišová, E., Ďuračka, M., Matušíková, I., \& Kačániová, M. (2020). Characterization of the Omija (Schisandra chinensis) extract and its effects on the bovine sperm vitality and oxidative profile during in vitro storage, Evidence-Based Complementary and Alternative Medicine, 2020, ID 7123780, 15 pages. https://doi.org/10.1155/2020/7123780

Vergun, O., Kačaniova, M., Rakhmetov, D., Shymanska, O., Bondarchuk, O., Brindza, J., \& Ivanišova, E. (2018). Antioxidant and antimicrobial activity of Bunias orientalis L. and Scorzonera hispanica L. Agrobiodiversity for Improving Nutrition, Health and Life Quality, 2, 29-38. https://doi.org/10.15414/ agrobiodiversity.2018.2585-8246.029-038.

Vergun, O., Rakhmetov, D., Shymanska, O., Bondarchuk, O., Ivanišová, E., Kačaniová, M., Grygorieva, O., \& Brindza, J. (2021). Assessment of antioxidant and antimicrobial activities of Crambe spp. during vegetation. Acta Scientiarum Polonorum Technologia Alimentaria, 20(2), 197-211. https://dx.doi.org/10.17306/J.AFS.2021.0927

Vergun, O., Shymanska, O., Ivanišová, E., \& Fishchenko, V. (2021). Antioxidant activity of wild Humulus lupulus L. Agrobiodiversity for Improving Nutrition, Health and Life Quality, 5(1), 47-54.

https://doi.org/10.15414/ainhlq.2021.0006
Vergun, O., Svydenko, L., Grygorieva, O., Shymanska, O., Rakhmetov, D., Brindza, J., \&Ivanišová, E. (2019). Antioxidant capacity of plant raw material of Scutellaria baicalensis Georgi. Potravinarstvo Slovak Journal of Food Sciences, 13(1), 614-621. http://doi.org/10.5219/1090

Vinogradova, Yu., Shelepova, O., Vergun, O., Grygorieva, O., \& Brindza, J. (2021). Phenolic content and antioxidant activity of Echinocystis lobata (Mich.) Torr. et Gray (Cucurbitaceae). Potravinarstvo Slovak Journal of Food Sciences, 15, 784-791. https://doi.org/10.5219/1579

Yezerska, O., Darmograj, R., Hudz, N., \& Levon, V. (2021). Prospects of the application of some species of the lamiaceae family and some features of the development of their tinctures: prospects of the appicationof some species of the Lamiaceae family. Agrobiodiversity for Improving Nutrition, Health and Life Quality, 5(1), 7279. https://doi.org/10.15414/ainhlq.2021.0008

Yim, S.Y., Lee, Y.J., Lee, Y.K., Jung, S.E., Kim, J.H., Kim, H.J., Son, B.G., Park, Y.H., Lee, Y.G., Choi, Y.W., \& Hwang, D.Y. (2009). Gomisin N isolated from Schisandra chinensis significantly induces anti-proliferative and pro-apoptotic effects in hepatic carcinoma. Molecular Medicine Reports, 2(5), 725-732. https://doi.org/10.3892/mmr 00000163

Yu, H.-R., Gao. X., Tian, Z.-K., \& Lun, W. (2017). Studies on the antioxidant activity of extracts from Schisandra chinensis. Amur Medical Journal, 4(20), 21-22. 